\title{
Extra naturam nulla salus? O drama e a esperança da criação e da religião na era do Antropoceno
}

\author{
Extra naturam nulla salus? \\ The drama and hope of creation and religion in \\ the Anthropocene era
}

\section{Resumo}

Nos encontramos imersos num desequilíbrio socioambiental sem precedentes. O objetivo deste artigo é analisar o que estamos fazendo com o mundo. O caminho escolhido foi de trilhar a temática a partir de três pontos: a) A Coisa a Pensar: o ponto mais crítico, com toda a sua atual e intrigante complexidade; b) A Coisa a Amar: o amor ao mundo, que deve despertar em todos nós uma esperança ecológica integral: da casa comum à comunhão de autonomias; c) A Coisa a Libertar: a Alegria da Criação. O artigo parte do pressuposto de que os dramas e as esperanças da Criação são os dramas e as esperanças da Religião. Diante da crise socioambiental do século XXI é preciso entender que o desafio maior que se coloca à religião é cuidar de Deus e da obra da criação. É preciso revisitar sempre os próprios conceitos de Imago Dei e de Imago hominis, para melhor entender a missão e a responsabilidade do humano no cuidado da Casa Comum.

Palavras-chave: Esperança. Criação. Ecologia. Religião. Mundo. Casa Comum.

\section{Abstract}

We found ourselves immersed in an unprecedented socioenvironmental imbalance. The purpose of this article is to analyze what 
we are doing with the world. The chosen path was to follow the theme from three points: a) The Thing to Think: the most critical point, with all its current and intriguing complexity; b) The Thing to Love: love for the world, which must awaken in us all an ecological hope: from the common house to the communion of autonomies; c) The Thing to Free: the Joy of Creation. The article assumes that the dramas and hopes of Creation are the dramas and hopes of Religion. In the face of the socio-environmental crisis of the 21 st century, it is necessary to understand that the greatest challenge facing religion is taking care of God and the work of creation. It is always necessary to revisit the very concepts of Imago Dei and Imago hominis, in order to better understand the human mission and responsibility in caring for the Common Home.

Keywords: Hope. Creation. Ecology. Religion. World. Common Home.

\section{Introdução}

Ao longo de vários meses, tenho convivido com dezenas de autores e dezenas de livros e artigos, debatendo-me com novos conceitos e com um banco infindável de dados e tratamento de dados disponibilizados por múltiplas áreas do saber. A minha dívida é grande para com todos, mas de modo particular para com Martin Heidegger e Zigmunt Bauman, que inspiram e conduzem, algumas vezes de modo subterrâneo, o estudo que vos apresento agora. O diálogo exploratório com estes autores forneceu-me bases para formular e testar hipóteses, ajudou-me a aprofundar uma ou outra intuição, a construir e a afinar categorias e a contrastar as minhas próprias posições.

Pelo meio, muitas foram as perplexidades, as hesitações metodológicas, o abandono ou validação de hipóteses e de princípios heurísticos; as próprias questões geradoras enfraqueceram, já para não falar do resvalo para a subjetividade, entre tantos outros escolhos que fazem parte dos processos de investigação. No entanto, este caminho, com estações árduas e por vezes angustiantes, conduziu a alguns resultados que, embora não tendo sido explicitamente previstos e visados, trazem, de certo modo, algo novo, uma descoberta para mim própria, no modo de aproximar aquilo a que Heidegger chamaria "o Ponto Mais Crítico", que se mostra, segundo ele "no que ainda não pensamos". E ele reforça: "Continuamos a não pensar, embora o estado 
do mundo continue, cada vez mais, a dar que pensar". ${ }^{1}$ Espero que esta minha tentativa nos possa aproximar um pouco mais do que ainda não pensamos, do Ponto Mais Crítico. Gostaria de entrar convosco por caminhos inesperados e pouco frequentados onde o risco de nos desorientarmos ou mesmo de nos perdermos é grande; mesmo assim, vale a pena a aventura: I - A Coisa a Pensar; II - A Coisa a Amar; III - A Coisa a Libertar.

\section{A Coisa a Pensar - O Ponto Mais Crítico}

Habitamos um universo simples e ao mesmo tempo de uma complexidade estonteante. É razoavelmente simples entrar na matemática, na biologia, na físico-química, mas é extremamente complexo para nós descrever e explicar a miríade de arranjos das unidades básicas de construção da matéria, que levam ao surgimento de formas de vida únicas, dinâmicas, sensitivas, capazes de pensamento e de sentimento.

A vida humana é ainda mais complexa na medida em que o indivíduo não se contenta com estar vivo; consciente de que as suas decisões mais básicas são condicionadas pelas possibilidades e limitações que a genética e o meio ambiente impõem, precisa de encontrar uma comunidade biótica mais vasta e complexa, um "nicho", onde possa desenvolver-se física, emocional e espiritualmente, onde se possa realizar, viver e ser feliz.

Comove-me as entranhas viver no planeta terra num arco temporal em que do registo de "desmesura antropocêntrica" que a Modernidade gerou, se passa, na segunda metade do século XX, durante a qual eu nasci, e neste século XXI infante, para um despertar em sobressalto da consciência ecológica planetária.

Observo com alegria e expetativa este progressivo despertar das consciências para a dimensão planetária e cósmica da mais ínfima vida e das relações intrínsecas que ligam todos os seres, com laços incindíveis de cumplicidade biótica. É emocionante ser agente e testemunha desta mudança de paradigma; o horizonte de realização da vida humana alarga-se e os conceitos antropológicos de vida boa e de bem viver revelam-se indissociáveis de todas as criaturas que habitam e constituem o planeta e o universo. Esta consciência é, ao mesmo tempo, "fascinante e tremenda"; fascinante, na medida em que configura uma nova "reverência" face ao mistério da vida, um mais profundo conhecimento quanto à natureza da vida e uma maior responsabilidade e

\footnotetext{
${ }^{1}$ HEIDEGGER, M., Que veut-dire “penser”?, p. 164.
} 
empatia para com a vida da natureza. Consciência tremenda, na medida em que se torna acessível ao senso comum e à experiência comum o processo vertiginoso de devastação do humano e do planeta em múltiplas vertentes, a desconstrução do "cosmo cultural" no qual nasceram as gerações que somos na atualidade, o colapso da religião tradicional no ocidente, o fim das utopias, a emergência abrupta de distopias, o fracasso estrondoso do ideal de progresso, o descrédito das soteriologias, a irrelevância e esquecimento de Deus, a "rendição dos deuses", ${ }^{2}$ o sentimento difuso de uma "última instância de humanidade" 3 e a incerteza relativamente ao futuro.

"O 'Eu' tão caro para o Homem do Ocidente, desfaz-se no urrar mudo de uma angústia impronunciável". ${ }^{4}$ Que lucidez ou que loucura fazem Maurice Bellet se expressar assim? Esta ideia resulta de uma leitura pessimista do mundo presente? Não seria justo conotar Maurice Bellet com um qualquer movimento pessimista; aliás, também nós nos distanciamos quer dos pessimismos quer dos otimismos - mais retóricas de adaptação e de acomodação de subjetividades à realidade do que a própria realidade. O que está aqui em questão é a tragédia da vida, mais do que qualquer outra coisa. Esse sentido trágico que a Grécia Antiga tão bem soube captar. É a maré alta do trágico do mundo presente que Bellet exprime, qual urrar mudo de angústias impronunciáveis do humano e da terra, sua companheira. Um presente trágico, grávido de ameaças e sem promessas de futuro. Um tempo, o nosso tempo, baralhado por dois ponteiros maiores: Renúncia (Chantal Delsol) e Nostalgia (Zygmunt Bauman). Renúncia, que Chantal Delsol explana na obra $L$ 'âge du renoncement:

A desconstrução e a demolição do que foi aviltado por excesso, esta desconstrução bem visível na segunda metade do século XX, deixa lugar a um outro estado de espírito: a renúncia. Trata-se, com efeito, menos de uma revolta ou de um pôr em causa, do que de um abandono, indiferente e frio: o momento presente desliga-se da verdade, da certeza, do progresso e da esperança, da realeza do homem e de tantas outras categorias ou conceções hierárquicas... o espírito contemporâneo não grita, nem suplica, nem agride. Ele deixa, ele enterra, ele livra-se de, ele demite-se. Ele afasta-se. ${ }^{5}$

\footnotetext{
${ }^{2}$ YOURCENAR, M., O tempo esse grande escultor, p. 11.

${ }^{3}$ LARUELLE, F., En dernière humanité.

${ }^{4}$ BELLET, M., Le Dieu sauvage, p. 24.

${ }^{5}$ DELSOL, C., L'âge du renoncement, p. 10-11.
} 
Nostalgia, para Zigmunt Bauman. O tempo presente é o tempo da nostalgia - "epidemia global de nostalgia" - que se exprime num movimento de "regresso às tribos", "regresso às desigualdades" e "regresso ao útero". A este movimento de fuga para outros lugares que não o futuro, Zigmunt Bauman chama-lhe "retrotopia", que é aliás, o título do seu último legado, obra publicada poucos meses após a sua morte, em 2017. "Então, qui estamos: os habitantes de uma era de perturbações e discrepâncias, um tipo de idade em que tudo - ou quase - pode acontecer, enquanto nada - ou quase - pode ser realizado com autoconfiança e certeza de o atravessar". ${ }^{6}$ É esta condição humana atual que o título deste estudo pretende focar: o drama e a esperança da criação e da religião na era do Antropoceno. Numa era polarizada não já entre a autoridade e o proibido, mas entre o possível e o impossível; entre conceções antropológicas essencialistas e conceções antropológicas relacionais; entre o "novo humanismo" e o trans-humanismo, entre uma perspetiva prometeica e pós-prometeica; entre uma antropologia de afastamento do humano da natureza e uma antropologia de imersão no seio da natureza. ${ }^{8}$

Extra naturam nulla salus? Facilmente associamos esta fórmula axiomática com o ambíguo e controverso axioma cristão - extra ecclesiam nulla salus - formalizado no século III por Cipriano de Cartago. A expressão que propomos é arriscada pelo estilo rebuscado que denota. Não se pretende, de modo algum, estabelecer qualquer paralelo semântico com o axioma cristão antigo; o recurso é meramente utilitário; reapropriamo-nos, tão só, da estrutura e lógica axiomáticas. O objetivo é provocar e mostrar qualquer coisa que dá que pensar, pela assertividade axiomática, pela ambiguidade e controvérsia que a própria formulação denota, pela diversidade e complexidade de abordagens, de leituras e de interpretações que indicia, ou seja, pelo seu carácter aberto a abordagens epistemológicas distintas, das biologias às teologias, das filosofias às geografias, passando pelas espiritualidades.

Fora da natureza não há salvação. Na medida em que a expressão der que pensar, cumpre o seu objetivo. Pensar a natureza, pensar a salvação e pensar o "fora" e o "dentro" que, para além da espacialidade, aponta para um terceiro sujeito nesta equação: o ser humano. No âmbito deste estudo, que se

\footnotetext{
${ }^{6}$ BAUMAN, Z., Retrotopia, p. 153.

${ }^{7}$ BOKOVA, I., L'UNESCO et les fondements du nouvel humanisme. Discurso da Diretora geral da UNESCO, em 07 de outubro de 2010, por ocasião da apresentação do diploma honoris causa em política europeia e internacional.

${ }^{8}$ PAPAUX, A., Homo faber, p. 536-540.
} 
inscreve na tentativa de aprendermos a pensar melhor a "Coisa Mais Crítica" que, no nosso tempo, se identifica com o desequilíbrio ecológico global, deixamos, simplesmente, uma nota de precisão concetual. O que dizemos quando dizemos natureza e o que dizemos quando dizemos salvação?

No que respeita à natureza, partilha-se o entendimento genérico de que natureza é um conceito complexo e dinâmico, com numerosos significados ao longo da história. No entanto, "Sendo um conceito vago é, todavia, uma palavra de grande peso que acompanha habitualmente argumentos vencedores", lembra Adrian Ivakhiv, professor de Pensamento Ambiental e Cultura na Universidade de Vermont's Rubenstein, nos Estados Unidos. Beneficiamos da boa síntese que o Professor faz do significado do conceito de natureza, identificando três grandes áreas de entendimento: “(i) a qualidade e carácter essencial de alguma coisa; (ii) a força inerente que conduz ou o mundo ou os seres humanos ou ambos; (iii) o mundo material em si mesmo, considerando os seres humanos incluídos ou não". ${ }^{10}$ Com esta base, se conseguirmos chegar a articular um conceito de natureza que não se identifica com "todas as coisas" ou com "o mundo todo" torna-se possível pensar o que pertence ou não pertence à natureza e que é essencial para pensar o fora ou dentro da natureza. ${ }^{11}$ Neste estudo, quando falamos de natureza situamo-nos no terceiro âmbito de sentido, referido por Adrian Ivakhiv, no qual o humano pode ser e não ser incluído; é incluído na medida em que, como ser biológico, partilha um mesmo nível de imanência; não é incluído, na medida em que o humano não é redutível a essa imanência; a capacidade de transcendência, singularidade do humano, outorga-lhe um nível distinto de participação na imanência.

É também no arco semântico deste terceiro sentido que o professor Adrien elabora uma genealogia das noções de natureza no Ocidente e que aqui replicamos; tal genealogia inclui, então:

A natureza concebida como um sistema de normas e leis, direitos e obrigações divinamente ordenado; um livro para ser lido, descoberto e estudado; o feminino maternal nutrindo e cuidando dos seus filhos (...); um organismo semelhante a um corpo cujas características espelham as do corpo humano; um objeto ou máquina como um relógio para ser analisado, desmontado e disponibilizado para o uso humano; um armazém

\footnotetext{
${ }^{9}$ IVAKHIV, A., Nature, p. 415.

${ }^{10}$ IVAKHIV, A., Nature, p. 415.

${ }^{11}$ EVERNDEN, N., The Social Creation of Nature, p. 20-21.
} 
de recursos; um reino duro e cruel do qual os humanos devem distanciar-se através do contrato social da civilização; uma teia de vida florescente; um jardim Edénico para ser protegido e visitado periodicamente para renovação e fortalecimento pessoal; um museu, parque temático, ou ginásio ao ar-livre para treinos da masculinidade ou conquistas sobre-humanas; um sistema cibernético ou base de dados de informação genética circulante; ou uma divindade, Gaia, que, quando pressionada, pode tornar-se um anjo vingador, exercendo justiça sobre a humanidade que transgrediu a sua ordem. ${ }^{12}$

Acrescentamos a este elenco, o estatuto de criatura, à semelhança dos demais seres, que as religiões em geral reconhecem à natureza, remetendo a sua origem para uma entidade divina criadora.

Cada um destes conceitos ou imagens configura diferentes tipos de relação do humano com a natureza: submissão, controle, exploração, instrumentalização, governo, predição, medida, manipulação, proteção, defesa ativa, contemplação estética, união mística. ${ }^{13} \mathrm{~A}$ identificação de múltiplos e diversificados modos de relação do humano com a natureza leva a pensar que a natureza não é um "óbvio guia para o comportamento humano"; 14 do mesmo modo, a ciência, que procura decifrar o mundo para nós, é múltipla, historicamente variável no modo como se relaciona com outros domínios, por exemplo, com a religião, com paradigmas culturais e políticos, com a sabedoria popular, com o próprio indivíduo, deixa uma grande margem de provisoriedade, de incerteza e de indeterminação, que favorece a emergência de diferentes e mesmo antagónicos tipos de relação com o mundo natural. Não será esta margem precisamente a terra natal do que chamamos e entendemos por liberdade? Não será esta margem o lugar favorável à emergência daquilo a que Polkinghorne chama "Truth-seeking comunities"? ${ }^{15}$ Não reside aqui precisamente aquilo a que uns chamam mistério e, outros, enigma da vida e do mundo? Aquilo que faz com que sejamos vida em movimento, num fascinante e tormentoso modo de ser peregrino? Peregrino fazedor de sentidos necessários para viver, necessários para querer viver e necessários para amar viver?

Por aqui começa a desenhar-se, em nosso entender, um critério de validação de guias seguros para o comportamento humano: o que é que o ser

\footnotetext{
${ }^{12}$ IVAKHIV, A., Nature, p. 416.

${ }^{13}$ IVAKHIV, A., Nature, p. 416.

${ }^{14}$ IVAKHIV, A., Nature, p. 416.

${ }^{15}$ POLKINGHORNE, J., The Faith of a Physicist, p. 149.
} 
humano pensa que é essencial para viver, para querer viver e para amar viver? Esta é, diria Heidegger, "a coisa a considerar" e a coisa a considerar é o "ponto crítico" e "toda a coisa crítica dá que pensar". Mas, adverte Heidegger, "nós somente podemos pensar quando amamos aquilo que é em si mesmo 'a Coisa a considerar'". ${ }^{16}$ Quererá Heidegger dizer com isto que o amor é condição essencial para o humano pensar bem? Se assumirmos este critério, seremos obrigados a reconhecer, como Heidegger: "o Ponto mais Crítico mostra-se nisto, que ainda não pensamos"; ${ }^{17}$ por um lado, porque não nos voltamos suficientemente para a Coisa a pensar, isto é, com amor - "longe da vista, longe do coração", diz o eloquente ditado popular - e, por outro lado, porque o que é preciso pensar se desvia do ser humano, esconde-se dele e reservase, embora o reservado já nos tenha sido e continua a ser apresentado; assim, o que se reserva, a essência da Coisa, solicita a atenção do humano de um modo mais essencial e reclama-o de um modo mais íntimo que qualquer outra coisa que lhe é apresentada. É ao humano que pertence encontrar e pensar o que se dá a pensar, mormente o que se dá a pensar em modo de reserva. É ao humano que cabe a tarefa de pensar para mostrar. Para Heidegger, "o homem é o ser que mostra; a sua essência é a de mostrador"18 daquilo que se afasta, daquilo que se reserva, e que é em si mesmo a Coisa que dá que pensar. Heidegger chama-lhe "O Ponto mais Crítico", e interroga-se: "O que é o Ponto mais Crítico? Em que é que ele se mostra no nosso tempo?"19 Replicamos a questão de Heidegger, hoje: Em que é que o Ponto Mais Crítico se mostra no nosso tempo? Não será, porventura, naquilo que nos convoca aqui: a falência ecológica global eminente? Inclino-me a pensar que sim.

Identificado o Ponto mais Crítico do nosso tempo, também o conceito de salvação, a que nos referimos no axioma extra naturam nulla salus, precisa de uma breve explicitação semântica, deixando depois o axioma aberto a outras possibilidades hermenêuticas.

As soteriologias de múltiplas naturezas, de modo particular, as soteriologias religiosas, apontam para a possibilidade de superação das limitações humanas provocadas por causas materiais, pelo sofrimento e pela morte. Embora o conceito de salvação esteja intimamente associado ao Cristianismo e à ideia de Jesus Cristo como Salvador, encontramos noutras

\footnotetext{
${ }^{16}$ HEIDEGGER, M., Que veut-dire “penser”?, p. 152.

${ }^{17}$ HEIDEGGER, M., Que veut-dire "penser”?, p. 153.

${ }^{18}$ HEIDEGGER, M., Que veut-dire “penser”?, p. 160.

${ }^{19}$ HEIDEGGER, M., Que veut-dire “penser”?, p. 153.
} 
religiões conceitos que veiculam a promoção da felicidade humana e têm como objetivo a transcendência da mortalidade. "A ideia de que o ser humano pode ser resgatado da condição defetiva em que se encontra ou transcender as limitações de causa material e a morte é um tema encontrado nas religiões". ${ }^{20}$

Nas religiões Abraâmicas, de um modo geral, a salvação aparece intrinsecamente ligada à escatologia; é compreendida em termos de perfeição deste mundo no fim da história e/ou em termos de plenitude individual, depois da morte, num mundo não material ou céu. A nossa hipótese - de salvação integral - passa por articular explicitamente e de modo intrínseco a salvação do ser humano e o mundo natural e a salvação do mundo natural e o ser humano. Penso que a soteriologia cristã, se purificada dos desvios e reducionismos que a inflação antropocêntrica provocou ao longo dos séculos, pode ainda trazer importantes contributos para pensar a salvação, no sentido de uma recapitulação salvífica de todas as criaturas, que o conceito soteriológico cristão de apocatastasis denota. Mais uma vez, Heidegger nos dá um critério e lembra um método para nos ajudar a pensar mais e a pensar novo a salvação que se dá a pensar como Coisa Crítica: "salvar não é somente livrar de um perigo, é propriamente libertar uma coisa, deixá-la voltar ao seu ser próprio". ${ }^{21}$ E para isso, o ser humano necessita de pensar a Coisa Crítica, aquela que dá que pensar; e só a pode pensar verdadeiramente na medida em que a ama e só a ama na medida em que a conhece, e só a conhece na medida em que experimenta aquele mais fundo do já pensado, que é reserva e ocultamento; na medida em que assume a vocação de mostrador da essência da Coisa Crítica; por outras palavras, na medida em que estabelece como método: "Procurar com o olhar por todos os lados, no interior do já pensado, o não pensado que ainda aí se esconde". ${ }^{22}$ Mas só se chega lá sob condição de amar aquilo que o pensamento procura, e o amor acontece precisamente no facto de se amar o que é/há de mais profundo. ${ }^{23}$

\section{A Coisa a Amar - Amor ao Mundo}

Sinto um grande gosto e deslumbre por pertencer a este tempo de radical mudança de paradigma no modo como o humano se compreende

\footnotetext{
${ }^{20}$ FLOOD, G., Salvation, p. 622.

${ }^{21}$ HEIDEGGER, M., Bâtir, Habiter, Penser, p. 177-178.

${ }^{22}$ HEIDEGGER, M., Que veut dire “penser?”, p. 165.

${ }^{23}$ HEIDEGGER, M., Que veut dire “penser?”, p. 164.
} 
a si mesmo e começa a entender o planeta Terra: como um condomínio no cosmo, geografia fechada, por um lado, pois é um lugar com bordos, fora do qual a expectativa de habitação para o humano ainda está no âmbito da ficção; por outro, condomínio aberto, na medida em que os humanos tomam progressiva consciência de que o planeta não é mera paisagem, nem teatro de operações, nem kit cósmico de sobrevivência, nem mera fonte inesgotável de recursos para fortalecer o sentimento de poder e de propriedade de alguns (temos presente a mais recente pretensão de Mr. Donald Trump, presidente dos Estados Unidos, que se propôs comprar a Gronelândia), nem armazém a céu aberto das construções e dejetos dos humanos. O planeta terra é um espantoso ser vivo, um ecossistema global que se abre como criatura-moradamoradora a uma infinidade de criaturas-moradas-moradoras. A esta luz, a relação biótica da criatura humana com toda a terra e com a terra toda, na intensividade e extensividade do seu ser planetário, nunca deveria ter sido na ordem do ter - expropriação, apropriação, exploração, consumo, mas sim na ordem do ser - ser-com, inter-esse, compaixão, sobriedade, humildade, evolução criativa, comunhão, condomínio, responsabilidade, amor.

Se é verdade que a terra é constituída por bens disponíveis, apetecíveis e consumíveis, na complexidade de relações tecidas no âmbito da cadeia alimentar, e de modo singular para o humano; se também é verdade que esta prodigalidade natural da terra exprime a sua intentio profundior de próexistência, de um modo pró-existente de ser; ela é, ao mesmo tempo, um bem perecível, quando forçada e ultrapassada a sua biocapacidade pela intervenção intensiva e pelo consumo irracional e desumano.

Vamos escutando, com um misto de estupefação e de impotência, a notícia relativa à data do earth overshot day - dia do ano até ao qual os humanos consomem os recursos disponíveis para todo o ano, ou seja, o dia do ano em que a terra atinge o limite da sua biocapacidade e, portanto, a partir do qual deixa de conseguir repor aquilo que consumimos. Em 2017, o earth overshot day foi assinalado no dia 03 de agosto; dois dias mais cedo, dia um de agosto, em 2018, e no ano em curso, 2019, o earth overshot day aconteceu a 29 de julho. A partir desta data, estamos a comer a terra, a empobrecê-la e a esgotá-la. Enfim, queremos lembrar aqui, de modo emblemático, que, logo no dia 19 de agosto, a Islândia assinalou o desaparecimento do primeiro glaciar devido às alterações climáticas.

A Presidente da República da Islândia, dizendo que pretende que seja declarado estado de emergência climático, descerra uma placa em memória 
do primeiro glaciar da ilha, o Okjokull, a perder a denominação de glaciar devido à extensa área gelada que desapareceu. Com a inscrição $A$ letter for the future está indicado o valor 415 ppm co2, que corresponde ao nível recorde de dióxido de carbono na atmosfera atingido em maio do ano passado. A terra deixou de ser o que era e sabemos que a terra que é hoje não é, afinal, a terra sonhada e prometida. Fizemos dela um lugar doentio e perigoso.

\section{A letter to the future}

Ok is the first Icelandic glacier to lose its status as a glacier.

In the next 200 years all our glaciers are expected to follow the same path.

This monument is to acknowledge that we know

what is happening and what needs to be done.

Only you know if we did it.

Afgúst 2019

415 ppm $\mathrm{CO}_{2}$

O earth overshot day e o desaparecimento do glaciar Okjokull são sinais inequívocos das consequências injustas, dramáticas e perigosas da ação humana sobre o planeta, nele provocando mudanças "globais" e "irreversíveis". Tal constatação leva a comunidade científica a identificar uma nova era geológica: o Antropoceno. ${ }^{24}$ No ano 2000, Crutzen e Stoermer forjam este neologismo para dizer que as alterações antropogénicas da Terra, alterações que resultam, portanto, da ação do ser humano, são tão profundas e globais ao ponto do humano se tornar uma "força geológica" que imprime mudanças irreversíveis no Planeta. Assim, à era do Cenozoico, sucede-se o Antropoceno, a nova era que é matriz da crise ecológica planetária atual, cujo grau de gravidade justifica as numerosas vozes que se levantam, pelo mundo a fora, para pedir a declaração de estado de emergência ecológica planetária e a declaração da ecologia integral, reforço eu, como TEIP: Território Educativo de Intervenção Prioritária.

${ }^{24}$ CRUTZEN, P. J.; STOERMER, E. F., The "Anthropocene", p. 17-18; BONNEUIL, C., Anthropocène, p. 35-40; CASTREE, N., The Anthropocene; LABRECQUE, C. A., Catholic Bioethics in the Anthropocene, p. 665-671. 
O planeta está em perigo pela ação do ser humano; poderá o ser humano salvar o planeta pela sua decisão e ação? O que é preciso mudar no nosso modo de ser e de habitar o mundo para alterar a rota de colisão para uma rota de comunhão?

\subsection{Esperança ecológica integral: da casa comum à comunhão de autonomias}

Duas Guerras Mundiais precedem a "Declaração Universal dos Direitos Humanos", proclamada em 1948. Desde esta declaração, onde o foco é o ser humano e a sua independência, até à Carta da Terra, no ano 2000, desenvolveu-se um movimento de progressiva deslocação do acento no ser humano independente para a interdependência. E da Declaração Universal dos Direitos Humanos à Declaração Universal dos Direitos da Mãe Terra (2010), passa-se do foco nos direitos e liberdades individuais para um foco nos direitos da comunidade maior da vida. Passar de privilegiar os direitos humanos para honrar também os direitos da natureza representa um grande arco de mudança. De modo concreto, a "Carta da Terra" dá-nos a aspiração por uma ecologia integral baseada na: 1) integridade ecológica; 2) justiça social e económica; 3) democracia, não-violência e paz; e 4) respeito e cuidado para com a comunidade de vida. Estes são documentos notáveis que refletem a mudança, ao longo do século XX, desde a valorização dos indivíduos isolados até à celebração da nossa imersão na comunidade da Terra. ${ }^{25} \mathrm{~A}$ coroar este movimento evolutivo, vem a encíclica papal Laudato Si (LS), em 2015; ela aponta e conduz para este sentido mais amplo das relações Humano-Terra: “...nós e todos os seres do universo... estamos unidos por laços invisíveis e formamos uma espécie de família universal, uma comunhão sublime". ${ }^{26}$

A bondade e a força da encíclica já foi por demais escrutinada e destacada. Tornou-se referência permanente no contexto do cristianismo católico, com o mérito de proporcionar uma síntese da condição ecológica planetária. Com a publicação da encíclica em 24 de maio de 2015, uma onda de pensamento sobre o planeta e a ecologia integral levantou-se notavelmente no contexto católico entrando na vaga global de um despertar em sobressalto para o "Ponto Crítico" da condição ecológica contemporânea - com incontáveis estudos, referências, criação de grupos de reflexão e de espiritualidade, projetos educativos, redes

\footnotetext{
${ }^{25}$ MICKEY, S. et al., The Variety of Integral Ecologies, p. xiii.

${ }^{26}$ LS 89.
} 
científicas interdisciplinares, manifestos, declarações, bandeira de ativismos "verdes" em múltiplos contextos políticos, culturais e sociais, para além da referência recorrente do título e subtítulo da encíclica. A LS cumpre, com efeito, a sua missão de catalisador de um vasto e diversificado leque de informação, de estudos, doutrinas, espiritualidades e ideais ecológicos; cumpre também a sua função de despertar as consciências individuais, as forças políticas, culturais e religiosas para o imperativo do cuidado integral da casa comum, configurado no conceito de ecologia integral.

Olhando os quatro anos de receção da encíclica, não será excessivo dizer que ela se tornou um marco axial do pensamento ecológico cristão e das teologias cristãs e fonte de inspiração criativa de um modo novo de pensar e de habitar o mundo. Coloca-nos no âmbito de uma problemática que se tornou forçosamente, diríamos mesmo, dramaticamente "interessante", ao longo das últimas décadas. Entenda-se aqui "interessante" no sentido que Heidegger explicita: "E 'interessante' quer dizer: o que permite ao objeto em questão tornar-se indiferente no momento após e ser substituído por um outro ... rebaixa a coisa interessante ao nível das indiferentes e será empurrada para o meio daquelas que em breve serão aborrecidas". ${ }^{27}$

No processo de receção da encíclica, esta é valorizada como síntese "interessante" e nova, por exemplo, na extensão do horizonte salvífico a todas as criaturas e ao processo de evolução criativa, esbatendo, assim, a clássica focalização antropocêntrica das soteriologias cristãs; "interessante", na medida em que deixa pontos de partida para o cristianismo repensar a teologia da criação, a soteriologia, a escatologia, tendo em conta os saberes das diferentes disciplinas científicas. "Interessante", ao reconhecer os vínculos intrínsecos entre todas as criaturas, nos quais se desenvolve e dos quais emerge, em aparente paradoxo, a irredutível autonomia dos indivíduos e se evidenciam as "leis intrínsecas" de cada um e de todos os seres - a este processo chamamos de bom grado: comunhão de autonomias, a plasmar no conceito de ecologia integral, que é a expressão secularizada das teologias cristãs da criação. E isto não é pouco! No entanto, o valor circunstancial - por isso, provisório e instável - do "interessante", poderá não ter interesse, se considerarmos, com Heidegger, que interesse, "inter-esse quer dizer: ser entre e no meio das coisas, manter-se no meio de uma coisa e aí permanecer sem fraquejar". ${ }^{28}$ Sobre o seu

\footnotetext{
${ }^{27}$ HEIDEGGER, M., Que veut dire “penser?”, p. 154.

${ }^{28}$ HEIDEGGER, M., Que veut dire “penser?”, p. 154.
} 
tempo, Heidegger diz: "o 'interesse' de hoje só conhece o 'interessante"”. ${ }^{29}$ Sobre o nosso tempo, poderemos sustentar o mesmo: o interesse de hoje parece só conhecer o interessante. A ser assim, este parece-nos ser um motivo forte para um trabalho de distanciamento crítico relativamente à própria Laudato $\mathrm{Si}$, enquanto considerada "interessante", na medida em que este distanciamento nos pode conduzir do interessante ao que tem "interesse" e do que é "interesse" e, por isso, nos colocar "no meio das coisas", nos aproximar do "Ponto Crítico", do "Ponto Mais Crítico", "do que se dá a pensar"30 e que é, para nós, a condição ecológica planetária e o estatuto e papel da Religião.

A título de exemplo de um modo reflexivo concreto de sustentar esta transição crítica do interessante para o interesse vejamos o conceito de casa comum; é um conceito interessante, mas que pode não ser o conceito com mais interesse, com mais potencial de inter-esse; que nos inter-essa e que nos coloca no Ponto Mais Crítico. No contexto da LS, dois verbos - pensar e habitar - aos quais acrescentamos um terceiro - morar - constituem o ponto de partida para algum distanciamento crítico relativo ao subtítulo da encíclica: Sobre o cuidado da casa comum. Ao ensaio de Heidegger, Bâtir, Habiter, Penser, vamos buscar os verbos pensar e habitar; ${ }^{31}$ a Levinas, no texto La Demeure, vamos buscar o verbo morar. ${ }^{32}$ Pensamos que um estudo aprofundado de cada um destes textos bem como o diálogo entre os dois poderá fornecer pistas para um pensar mais original e para uma compreensão renovada do ser humano como aquele que habita, na medida em que o habitar é o seu modo de ser na terra, ${ }^{33}$ mas explorando outras semânticas do habitar, que a distinção entre casa e morada pode trazer. No âmbito desta conferência, não é possível levar mais longe o estudo do potencial desta intuição. Fica a hipótese de trabalho. O jogo entre habitação (Heidegger) e morada (Levinas) serve, em nosso entender, para fundamentar o necessário distanciamento crítico relativamente às semânticas de cuidado e de casa comum, sugerindo assim, um novo capítulo na encíclica Laudato $S i$ ' ou uma renovada edição. Parece-me que uma Laudato Si' 2 poderia conduzir a categoria de cuidado a outras representações do habitar a terra, para além da casa comum. Implicaria, por um lado, a distinção entre casa e morada e, por outro lado,

\footnotetext{
${ }^{29}$ HEIDEGGER, M., Que veut dire “penser?”, p. 154.

${ }^{30}$ HEIDEGGER, M., Que veut dire “penser?”, p. 154-158.

${ }^{31}$ HEIDEGGER, M., Bâtir, Habiter, Penser, p. 170-193.

${ }^{32}$ LEVINAS, E., La demeure in Totalité et Infini, p. 162-190.

${ }^{33}$ HEIDEGGER, M., Bâtir, Habiter, Penser, p. 173. 175.
} 
a identificação 'adam-adamah, identificação do Humano com a Terra, a chamada casa comum; identificação, não simbólica ou alegórica, mas física e, claro, tendo em conta os níveis distintos de imanência e de participação na imanência. Implicaria pensar a casa comum não como um dado (que o título cuidado da casa comum sugere), mas como um in fieri, como possibilidade de construção-habitação-morada comum necessariamente ligada à construção da humanidade comum.

Em suma, propomos a categoria de morada como mais adequada do que casa para dizer o modo de ser-estar do humano na terra, e a cidade, a Polis, que, diz Aristóteles, "não é mais que uma associação de seres iguais, que aspiram em comum a conseguir uma existência ditosa e fácil", ${ }^{34}$ mais adequada do que casa para dizer a comunhão planetária de autonomias, vejase, para dizer ecologia integral.

\section{A Coisa a Libertar - A Alegria da Criação}

Os dramas e as esperanças da Criação são os dramas e as esperanças da Religião. Hoje:

a) O desafio maior que se coloca à Religião é cuidar de Deus. Chegados ao século XXI, parece que pouo restou - em todo o caso, do Deus da e na religião - e o que restou não parece ter significativo interesse para os Modernos. Deus tornou-se uma inutilidade "mundana" (Claude Geffré); Não mais suscita admiração, nem temor, nem interesse prático; tornou-se uma curiosidade envolta em bolor e pó; se ainda vem à ideia (Emanuel Lévinas) não é para pensar ou ser pensado (Adolphe Gesché), muito menos amado, mas para ser relegado para uma arqueologia das ideias, quando não para o esquecimento. Deus está ao abandono. O fascinans et tremendum do Deus do monoteísmo hebraico e cristão não o é mais e "O apagamento da transcendência deixa o mundo terrestre solitário". ${ }^{35}$ Certo é que, ao encontrar-se numa terra sem céu, nos limites da simples imanência, o humano ressente-se desta condição. Charles Taylor descreve-a em termos de "mal-estar da imanência", dele identificando três formas: a fragilidade do sentido, o

\footnotetext{
${ }^{34}$ ARISTÓTELES, A Política, p. 216.

${ }^{35}$ DELSOL, C., L'âge du Renoncement, p. 46.
} 
nivelamento das nossas tentativas para solenizar momentos cruciais de transição nas nossas vidas e o absoluto nivelamento, esvaziamento, do ordinário. ${ }^{36}$

As Religiões têm diante de si a missão histórica de cuidar de Deus e de habitar com empatia e coragem profética os abismos da imanência.

b) Resta a esperança de que, e as palavras são de Schleirmacher, "Das suas peregrinações através todo o domínio da humanidade, a religião regresse com um sentido mais afinado e um julgamento mais formado, entre no seu próprio eu e encontre finalmente em si mesma tudo aquilo que, tirado das regiões mais afastadas, ela procurou reunir". ${ }^{37}$ Vale a pena visitar de novo os Discours sur la Religion, de Schleirmacher, particularmente o Segundo Discurso. Pode ajudar-nos a repensar a religião, hoje, e o cristianismo de um modo particular.

Parece-me imperativo recuperar e valorizar dimensões da religião retidas no crivo do iluminismo e da racionalidade teológica e colocadas sob suspeita: contemplação, intuição, sentimento. Estes são os elementos que, segundo Schleirmacher, definem a religião; diz ele: "Na sua essência, ela não é nem pensamento, nem ação, mas contemplação intuitiva e sentimento". ${ }^{38}$ Tal não significa a marginalidade da razão. Schleiermacher ainda sublinha: "A religião deve ser qualquer coisa que tem a sua realidade própria, que pode penetrar no coração dos homens, qualquer coisa de pensável, que pode ser objeto de um conceito, sobre o qual se pode dissertar e discutir". ${ }^{39}$ A esta luz, a religião é, certo, contemplação, intuição, sentimento, mas também pensamento, de Deus e do Universo.

As Religiões têm diante de si a missão histórica de cuidar do seu património religioso e de o disponibilizar ao mundo de hoje com humildade generosa e imaginação criativa.

c) A Religião tem escrita uma história milenar de revelação e de experiência de um Amor Maior que move o mundo no sentido da alegria e da salvação. A Religião pode dar um contributo fundamental para a

${ }^{36}$ TAYLOR, C., A secular age, p. 309.

${ }^{37}$ SCHLEIERMACHER, F., Discours sur la Religion, p. 182.

${ }^{38}$ SCHLEIERMACHER, F., Discours sur la Religion, p. 151.

${ }^{39}$ SCHLEIERMACHER, F., Discours sur la Religion, p. 149. 
transformação do modo como cada indivíduo se vê a si mesmo e na relação com o que o rodeia, ao nível do que poderíamos chamar "experiência mística da íntima relação com todas as criaturas". "Aquilo de que precisamos, em primeiro lugar, não é de uma teologia ecológica multirreligiosa, mas de uma profunda reorientação das consciências, considerando a nossa identidade como seres comunitários". ${ }^{40}$ As Religiões estarão à altura deste papel místico, se velarem para que não se fechem as poucas brechas de transcendência no cosmo e, ao mesmo tempo, se procurarem trazer à luz o elemento que falta: o amor, pois só ele jamais nos deixará indiferentes ao grito da criação e ao grito dos pobres. ${ }^{41}$

Com efeito, enquanto os factos não tocarem o coração do humano não haverá amor compassivo e sem amor compassivo não há transformação do mundo. A realidade é que não temos sabido reconhecer todas as criaturas e todas as coisas como "carícia" total de Deus, ${ }^{42}$ teremos, por isso, pela frente a árdua tarefa de compensar 20 séculos de desmesura antropocêntrica. É necessário portanto, investir num movimento de transformação-conversão de dentro para fora. E aqui as Religiões podem dar um contributo fundamental.

d) O diálogo entre a ciência e religião precisa de focar-se em questões e tópicos específicos e não em discursos genéricos. Esse tipo de diálogo interessa aos dois interlocutores. Por exemplo, no âmbito da condição ecológica atual, "em vez de simplesmente oferecerem uma síntese de alguma idealizada interação com a natureza", ${ }^{43}$ as religiões precisam se envolver cada vez mais nas problemáticas ambientais, culturais e sociais concretas dos indivíduos, numa frente conjunta com os saberes em geral e particularmente com as ciências do ambiente. Esta frente conjunta representa uma tentativa comum - pacífica e reflexiva - para resolver problemas práticos urgentes que afetam a qualidade da vida humana e o destino das diversas espécies e ecossistemas da terra. ${ }^{44}$

\footnotetext{
${ }^{40}$ COWARD, H.; MAGUIRE, D., Visions of a New Earth, p. 208.

${ }^{41}$ LS 49.

${ }^{42}$ LS 84.

${ }^{43}$ BRATTON, S., Ecology and Religion, p. 222.

${ }^{44}$ BRATTON, S., Ecology and Religion, p. 222.
} 
e) Também as Religiões têm o dever de intensificar o diálogo globalmente responsável - ecuménico e inter-religioso - e de se mobilizarem numa frente comum de profecia: de esperança para a Terra, de esperança para a criação. Uma esperança em movimento, capaz de imprimir "mudanças decisivas na peregrinação da justiça e da paz". Esta é a convicção e o programa de ação transmitidos pela Conferência inter-religiosa realizada entre 16-19 de junho de 2019, em Wuppertal na Alemanha, "Kairos para a criação - Confessando esperança para a Terra": ${ }^{45}$ coragem, num tempo de ansiedade e desespero, para que todos nos sintamos inspirados a participar no cuidado integral da criação. Pelo diálogo globalmente responsável, as Religiões estarão a contribuir para a salvação da beleza e bondade do mundo, ao mesmo tempo que partilham as riquezas das diferentes tradições religiosas.

f) Revisitar o conceito de Imago Dei na tradição bíblica e teológica do Cristianismo pode trazer chaves críticas para pensar a Imago hominis - o humano criado à imagem de si mesmo - da era do Antropoceno. Aqui, a tradição hebraico-cristã pode assumir uma palavra singular no âmbito da ecologia humana, mormente no que respeita à dignidade humana e aos direitos humanos.

g) A peregrinação da justiça e da paz na era do Antropoceno toca o sinal de alarme, chegada à estação trágica de emergência ecológica global. Formulo ainda um último desafio, por entre tantos outros que ficam por enunciar, à espera que o nosso encontro com as dores e as cruzes do mundo inspire modos novos de ser benfazejos e desperte em nós o Espírito que renova a face da terra. Desafio que se formula em termos de medida concreta: proponho que comecemos a considerar seriamente a possibilidade de um Rendimento Básico Universal (RBU), como um direito-devido humano universal para lutar contra as desigualdades, promover a liberdade e autodeterminação de cada membro da família humana e contribuir para dinâmicas de convivência feliz entre todas as criaturas. Originalmente a ideia tinha em vista o âmbito mais restrito de um país - todos os cidadão deveriam ter um rendimento básico nacional, aquele que é devido à sobrevivência de todos e de cada

${ }^{45}$ CONFERÊNCIA WUPPERTAL EM ECO-TEOLOGIA E DE ÉTICA DA SUSTENTABILIDADE, O Wuppertal Call - Kairos para a Criação - Confessante esperança para a Terra. 
cidadão e coloca todos num patamar a partir do qual cada um pode florescer, crescer, desenvolver-se, realizar-se, competir, consumir e produzir riqueza. Recentemente, esta minha ideia embrionária evoluiu para o âmbito universal, ao encontrar em Zigmunt Bauman a proposta de um Universal Basic Income (UBI). ${ }^{46}$ Subscrevo a sua convicção de que um RBU ou UBI pode constituir um ganho social, moral, político, cultural e ecológico sem precedentes no combate às desigualdades e aos desequilíbrios em todos os âmbitos da vida no planeta.

\section{Conclusão}

Tendo trilhado os caminhos propostos e feito a reflexão a partir de três pontos: a) A Coisa a Pensar: O ponto mais crítico; b) A Coisa a Amar: o amor ao mundo; c) A Coisa a Libertar: A Alegria da Criação, sempre a partir dos ângulos propostos, como ótica de leitura, somos convidados a olhar os dramas da Criação, diante da crise socioambiental do século XXI, tendo presente que esta crise desafia a religião a cuidar de Deus e da obra da Criação, revisitando sempre o próprio conceito de Imago Dei e de Imago hominis, à luz da Revelação e da experiência de um Amor Maior que move o mundo no sentido da alegria e da salvação.

Não somos mais ingénuos. A intrigante e perigosa realidade ecológica do mundo presente desafia a todos a "inventar" um modo novo de habitar o planeta, que nos possa levar da casa comum à comunhão de autonomias; que nos possa ajudar a ter sempre presente que os dramas e as esperanças da Criação são os dramas e as esperanças da Religião.

Se a crise sociambiental nos questiona e nos desafia, então é preciso entender que o desafio maior que se coloca à religião neste momento é cuidar da obra da criação, procurando estabelecer sempre e cada vez mais o diálogo entre a ciência e a religião, inclusive focando-se em questões e tópicos mais emergentes e não em discursos genéricos. É missão das Religiões identificar causas concretas e colocar-se na linha da frente da não resignação, da denúncia do mal e do anúncio operativo de boas novas e da boa nova da salvação, aqui e agora.

Imperioso é que tenhamos presente que as Religiões têm o dever de intensificar um diálogo globalmente responsável, seja aquele ecuménico,

${ }^{46}$ BAUMAN, Z., Retrotopia, p. 83-117. 
seja aquele interreligioso. Mais ainda, as Religiões devem mobilizar-se numa frente comum de profecia: de esperança para a Terra, para o Planeta, para a Criação como um todo e não apenas para os Humanos. Não somos mais cegos. Não somos mais surdos. Vemos e ouvimos a peregrinação da justiça e da paz na era do Antropoceno tocar o sinal de alarme ao chegar à estação trágica de emergência ecológica global. Para Zigmunt Bauman, "Temos diante de nós o caminho aberto ou para darmos as mãos ou para abeirarmos a sepultura comum". ${ }^{47}$

No momento certo, no lugar certo, do modo certo, o papa Francisco encontra as palavras certas para exprimir o que todos intuímos e acalentamos nos nossos corações:

Como nunca antes na história, o destino comum obriga-nos a procurar um novo início (...). Que o nosso seja um tempo que se recorde pelo despertar duma nova reverência face à vida, pela firme resolução de alcançar a sustentabilidade, pela intensificação da luta em prol da justiça e da paz e pela jubilosa celebração da vida. ${ }^{48}$

Enfim, ressoa nos nossos ouvidos, nos nossos pensamentos e nos nossos corações, o convite de Geraldo Vandré para caminharmos; caminharmos, cantando, sem medo: "Vem vamos embora que esperar não é saber, quem sabe faz a hora não espera acontecer; vem vamos embora que esperar não é saber, quem sabe faz a hora, não espera acontecer". ${ }^{49}$

\section{Referências bibliográficas}

ARISTÓTELES. A Política. Lisboa: Editorial Presença, 1965.

BAUMAN, Z. Retrotopia. Cambridge: Polity Press, 2018.

BELLET, M. Le Dieu sauvage: Pour une foi critique. Paris: Bayard, 2007.

BOKOVA, I. L'UNESCO et les fondements du nouvel humanisme. Discurso da Diretora geral da UNESCO, em 07 de outubro de 2010, por ocasião da apresentação do diploma honoris causa em política europeia e internacional.

\footnotetext{
${ }^{47}$ Com estas palavras, Zigmunt Bauman encerra a sua última obra escrita: BAUMAN, Z., Retrotopia, p. 167.

${ }^{48}$ LS 207. Neste excerto literal os negritos são acrescentados por mim.

${ }^{49}$ VANDRÉ, G., Pra não dizer que não falei das flores...
} 
Disponível em: $<$ http://www.unesco.org/new/pt/brasilia/about-this-office/single-view/news/unesco_and_the_new_humanism_principles/>. Acesso em: 02 set. 2019.

BONNEUIL, C. Anthropocène. In: BOURG, D.; PAPAUX, A. (Dir.). Dictionnaire de la pensée écologique. Paris: PUF, 2015. p. 35-40.

BRATTON, S. Ecology and Religion. In: CLAYTON, P.; SIMPSON, Z. The Oxford Handbook of Religion and Science. Oxford: Oxford University Press, 2008. p. 207-225.

CASTREE, N. The Anthropocene: a primer for geographers. Geography, v.100, p. 66-75, 2015.

CONFERÊNCIA WUPPERTAL EM ECO-TEOLOGIA E DE ÉTICA DA SUSTENTABILIDADE. O Wuppertal Call - Kairos para a Criação - Confessante esperança para a Terra. Disponível em: $<$ https://jliflc.com/resources/kairos-for-creation-confessing-hope-for-the-earth-the-wuppertal-call/>. Acesso em: 02 set. 2019.

COWARD, H.; MAGUIRE, D. Visions of a New Earth: religious perspectives on population, consumption and ecology. Albany: State University of New York Press, 2000.

CRUTZEN, P. J.; STOERMER, E. F. The "Anthropocene". Global Change Newsletter, n.41, p. 17-18, may. 2000.

DELSOL, C. L'âge du renoncement. Paris: Cerf, 2011.

EVERnDEN, N. The Social Creation of Nature. Baltimore, MD: Johns Hopkings University Press, 1999.

FLOOD, G. Salvation. In: STAUSBERG, M.; ENGLER, S. (Ed.). The Oxford Handbook of the Study of Religion. United Kingdom: Oxford University Press, 2016. p. 622-633.

HEIDEGGER, M. Bâtir, Habiter, Penser. In: HEIDEGGER, M. Essais et Conférences. Paris: Gallimard, 1958. p. 177-178.

HEIDEGGER, M. Que veut-dire “penser"?. In: HEIDEGGER, M. Essais et Conférences. Paris: Gallimard, 1958. p. 152-165.

IVAKHIV, A. Nature. In: STAUSBERG, M.; ENGLER, S. (Ed.). The Oxford Handbook of the Study of Religion. United Kingdom: Oxford University Press, 2016. p. 415-429. 
LABRECQUE, C. A. Catholic Bioethics in the Anthropocene. Integrating Ecology, Religion, and Human Health. The National Catholic Bioethics Quarterly, v.15, n.4, p. 665-675, 2015. Disponível em: <https:/www.pdenet. org/ncbq/content/ncbq 2015_0015_0004_0665_0671>. Acesso em: 02 set. 2019.

LARUELLE, F. En dernière humanité: La nouvelle science écologique. Paris: Cerf, 2015.

LEVINAS, E. La demeure. In: LEVINAS, E. Totalité et Infini: Essai sur l'extériorité. Paris: Kluwer Academic, 1994. p. 162-190.

MICKEY, S. et al. The Variety of Integral Ecologies: Nature, Culture, and Knowledge in the Planetary Era. EBSCOhost: SUNY Press, 2017.

PAPAUX, A. Homo faber. In: BOURG, D.; PAPAUX, A. (Dir.). Dictionnaire de la pensée écologique. Paris: PUF, 2015. p. 536-540.

POLKInGHORNE, J. The Faith of a Physicist: Reflections of a Bottom-up Thinker. Princeton: University Press, 1994.

SCHLEIERMACHER, F. Discours sur la Religion: A ceux de ses compteurs que sont des Esprits cultivés - 1789. Paris: Aubier Montaigne, 1944.

TAYLOR, C. A secular age. Cambridge: Harvard University Press, 2007.

YOURCENAR, M. O tempo esse grande escultor. Miraflores: Difusão Editorial, 2015.

Maria Isabel Pereira Varanda

Doutora em Teologia pela Universitè Catolique de Louvain Docente do Departamento de Teologia da Universidade Católica Portuguesa Braga - Portugal E-mail: mivaranda@gmail.com

Recebido em: 13/10/2019

Aprovado em: 15/03/2020 